\title{
Atividade antibacteriana de citronelal e citronelol contra cepas de Escherichia coli produtoras de ESBL
}

Antibacterial activity of citronellal and citronelol against strains of Escherichia coli ESBL producers Actividad antibacteriana de citronelal y citronelol contra cepas de Escherichia coli productoras de ESBL Dijaci Santos de LIMA ${ }^{\mathbf{1}}$

Maria Alana Neres de PONTES ${ }^{2}$

Francisco Patricio de ANDRADE JÚNIOR ${ }^{3}$

Bernadete Helena Cavalcanti dos SANTOS ${ }^{4}$ Wylly Araújo de OLIVEIRA ${ }^{5}$

Igara Oliveira LIMA $^{5}$

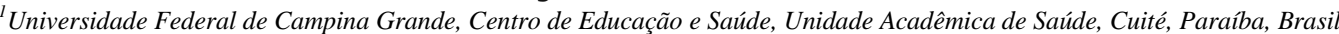

${ }^{2}$ Universidade Federal de Campina Grande (UFCG) Campus Cuité

${ }^{3}$ Mestre e Doutorando pelo Programa de Pós-Graduação em Produtos Naturais e Sintéticos Bioativos, área de concentração em Farmacologia, Universidade Federal de Campina Grande (UFCG)

${ }^{4}$ Farmacêutica (Técnica de Nível Superior) na Disciplina de Microbiologia Clínica, Universidade Federal da Paraíba, Centro de Ciências da Saúde, Departamento de Ciências Farmacêuticas, João Pessoa, Paraíba, Brasil

${ }_{5}^{5}$ Professor(a) da Universidade Federal de Campina Grande (UFCG) Campus Cuité

\section{Resumo}

Introdução: A bactéria Escherichia coli é um bacilo Gram negativo que pode causar o desenvolvimento de infecções, principalmente, no trato gastrointestinal, podendo levar os acometidos a óbito. Além disso, houve o surgimento de cepas produtoras de betalactamases de amplo espectro (ESBL), que se caracterizam por apresentarem-se resistentes a diversos $\beta$-lactâmicos, sendo necessária a busca por novas substâncias com atividade antibacteriana frente a esses microrganismos. Objetivo: O presente trabalho teve como objetivo estudar a atividade antimicrobiana dos fitoconstituintes citronelal e citronelol contra cepas de Escherichia coli ESBL através da determinação da concentração inibitória mínima (CIM). Materiais e métodos: A determinação da CIM dos fitoconstituintes selecionados foi realizada pela técnica da microdiluição seriada a uma razão de dois, reservando a última coluna para o controle do crescimento dos microrganismos. Resultados: A CIM do citronelol apresentou concentrações de $256 \mu \mathrm{g} / \mathrm{ml}$ para as cepas C-18, 65, 21 e C-20, e $512 \mu \mathrm{g} / \mathrm{ml}$ para as cepas C-24, C-25, 24 e 45. Já frente à ação do citronelal não se foi possível a obtenção da CIM nas concentrações testadas. Conclusão: Através dos experimentos pôdese afirmar que o fitoconstituinte citronelol exerce atividade bacteriostática sobre as cepas de Escherichia coli e que o fitoconstituinte citronelal não possui atividade antibacteriana nas concentrações testadas.

Descritores: Escherichia coli; Antibacterianos; Terpenos; Farmacologia.

\section{Abstract}

Introduction: The bacterium Escherichia coli is a Gram negative bacillus that can cause the development of infections, especially in the gastrointestinal tract, which can lead to death. In addition, there was the emergence of broad spectrum beta-lactamase producing strains (ESBL), which are characterized by being resistant to several $\beta$-lactams, requiring the search for new substances with antibacterial activity against these microorganisms. Objective:This work aims to study the antimicrobial activity of phytochemicals citronellal and citronellol against strains of Escherichia coli ESBL though determination of the minimum inhibitory concentration (MIC). Material and methods: The determination of the MIC of the selected phytochemicals was performed by the technique of serial microdilution in a ratio of two, reserving the last column to control the growth of microorganisms. Results: The CIM citronellol showed concentrations of $256 \mathrm{ug} / \mathrm{ml}$ for C-18 strains, $65,21, \mathrm{C}-20$ and $512 \mathrm{~g} / \mathrm{ml}$ for the strains C-24, C-25 and front 24 and 45. Since the action of citronelol not been possible to obtain the CIM at the concentrations tested. Conclusion: Through the experiments could be said that the citronelol fitoconstituinte has bacteriostatic activity against the strains of Escherichia coli and the cintronelal fitoconstituinte not have antibacterial activity in the tested concentrations.

Descriptors: Escherichia coli; Anti-Bacterial Agents; Terpenes; Pharmacology.

\section{Resumen}

Introducción: La bacteria Escherichia coli es un bacilo Gram negativo que puede causar el desarrollo de infecciones, especialmente en el tracto gastrointestinal, que puede conducir a la muerte. Además, surgieron cepas productoras de betalactamasas de amplio espectro (BLEE), que son resistentes a varios $\beta$-lactámicos, así es necesária la búsqueda de nuevas sustancias con actividad antibacteriana contra estos microorganismos. Objetivo: El presente trabajo tuvo como objetivo estudiar la actividad antimicrobiana de los fitoconstituyentes citronellal y citronelol contra cepas de ESBL de Escherichia coli mediante la determinación de la concentración inhibitoria mínima (CIM). Materiales y métodos: La determinación de la CIM de los fitoconstituyentes seleccionados se realizó mediante la técnica de microdilución en serie en una proporción de dos, reservando la última columna para controlar el crecimiento de microorganismos. Resultados: Citronelol MIC presentó concentraciones de $256 \mu \mathrm{g} / \mathrm{ml}$ para las cepas C-18, 65, 21 y C-20 y $512 \mu \mathrm{g} / \mathrm{ml}$ para las cepas C-24, C-25, 24 y 45 . La acción de citronelal no fue posible obtener la MIC a las concentraciones probadas. Conclusión: A través de los experimentos, se puede afirmar que el fitoconstituyente del citronelol ejerce actividad bacteriostática en las cepas de Escherichia coli y que el fitoconstituyente del citronelal no tiene actividad antibacteriana en las concentraciones probadas.

Descriptores: Escherichia coli; Antibacterianos; Terpenos; Farmacología.

INTRODUÇÃO

A bactéria Escherichia coli é um bacilo Gram negativo que pode ser encontrado comumento na região intestinal de animais, incluindo seres humanos, ou ser adquirida através da ingestão de alimentos e água contaminados ocasionando no surgimento de diversas doenças, principalmente, no trato gastrointestinal, podendo levar o acometido a óbito ${ }^{1}$.

Infecções geradas por este microrganismo, há décadas atrás, eram combatidas através da utilização de cefalosporinas, contudo após o surgimento de cepas produtoras de betalactamases de amplo espectro (ESBL), o uso desses fármacos tornou-se ineficaz ${ }^{2-4}$, observando-se que somente alguns antimicrobianos $\beta$-lactâmicos conservam sua atividade frente a cepas produtoras de ESBLs ${ }^{2,5,6}$.

Devido à inefetividade das principais formas de tratamento contra infecções bacterianas de cepas produtoras de ESBL, pesquisas têm sido desenvolvidas no intuito de investigar novos fármacos com ação antimicrobiana, em que se pode constatar grande potencial dos produtos naturais como possíveis agentes antibacterianos ${ }^{7,8}$, a exemplo dos terpenos. 
Os terpenos e seus derivados estão geralmente associados aos óleos essenciais, se caracterizando por serem compostos voláteis formados por unidades de isopreno $\left(\mathrm{C}_{5} \mathrm{H}_{8}\right) \mathrm{n}$ e que apresentam diversas funções químicas orgânicas, como ácidos, aldeídos, cetonas, fenóis, entre outros. Dentre os diversos terpenos, é possível destacar citronelol e citronelal que são formados por duas unidades de isopreno e possuem a função orgânica álcool e aldeído, respectivamente ${ }^{9}$.

O citronelol está presente em óleos essenciais de algumas plantas medicinais como Cymbopogon citratus, Cymbopogon winterianus e Lippia alba ${ }^{10}$, enquanto que o citronelal pode ser encontrado em óleo essencial de Cymbopogon nardus ${ }^{11}$. Ambos os monoterpenos têm sido investigados frente a sua atividade bactericina e/ou bacteriostática, entretanto nota-se escassez de estudos quanto ao seu potencial antibacteriano frente cepas produtoras de ESBL.

Assim, o presente estudo teve como objetivo avaliar, através do método de microdiluição em caldo, a atividade antibacteriana de citronelal e citronelol frente a cepas de Escherichia coli produtoras de ESBL.

\section{MATERIAL E MÉTODO}

\section{- Cepas bacterianas e fitoconstituintes}

Foram utilizadas as cepas bacterianas de $E$. coli ESBL C-18, 65, C-21, C-20, C-24, C-25, 24 e 45 e os fitoconstituintes testados foram o citronelal e o citronelol adqueridos através da empresa Sigma Aldrich.

\section{○ Inóculo}

O inóculo foi ajustado de acordo com a escala de 0,5 Mc Farland em uma suspensão composta pela bactéria e por solução salina à $0,85 \%$.

\section{- Determinação da Concentração Inibitória Mínima (CIM)}

A determinação da CIM dos fitoconstituintes selecionados foi realizada pela técnica da microdiluição em placa de 96 cavidades e fundo em "U" para cada uma das cepas. Através da diluição seriada a uma razão de dois, foram obtidas as concentrações de 1024 a $32 \mu \mathrm{g} / \mathrm{mL}$, efetuadas na própria placa, da coluna $\mathrm{A}$ até a $\mathrm{F}$. As duas últimas colunas $(\mathrm{G} \mathrm{e} \mathrm{H})$ foram reservadas para o controle de crescimento do microrganismo (caldo Müeller Hinton, sem o produto testado). Foram realizados os seguintes controles: controle para observar a viabilidade da cepa (caldo e cepa) e controle de esterilidade (caldo) ${ }^{12-14}$.

Em seguida, adicionou-se $10 \mu \mathrm{L}$ do inóculo (bactéria a 0,5 McFarland) em cada uma das cavidades. $\mathrm{O}$ ensaio foi realizado em triplicata $\mathrm{e}$ incubado a $37^{\circ} \mathrm{C}$ no período de 24 horas para E. coli. Após o tempo de incubação adequado, $20 \mu \mathrm{L}$ resazurina a $1 \%$ (SIGMA), indicador colorimétrico de óxido-redução para bactérias, foi adicionado e a leitura procedida, visualmente, pela ausência ou presença de crescimento do microrganismo através da observação da mudança da coloração da solução de azul para rosa/vermelho, resultante do crescimento do microrganismo. Portanto, foi determinada como CIM, a menor concentração do produto capaz de inibir o crescimento do microrganismo ensaiado ${ }^{12-14}$.

RESULTADOS

Os resultados referentes à ação bacteriostática do citronelol contra cepas de $E$. coli se encontram na Tabela 1.

Tabela 1. Concentração Inibitória Mínima (CIM em $\mu \mathrm{g} / \mathrm{ml})$ do citronelol contra cepas de E. coli

\begin{tabular}{c|c|c}
\hline Cepas & Controle Positivo & Citronelol $(\boldsymbol{\mu g} / \mathbf{m L})$ \\
\hline $\mathrm{C}-18$ & + & 256 \\
\hline 65 & + & 256 \\
\hline 21 & + & 256 \\
\hline $\mathrm{C}-20$ & + & 256 \\
\hline $\mathrm{C}-24$ & + & 512 \\
\hline $\mathrm{C}-25$ & + & 512 \\
\hline 24 & + & 512 \\
\hline 45 & + & 512 \\
\hline +Crescimento Bacteriano & &
\end{tabular}

Na Tabela 2 pode-se observar que não se foi possível à obtenção da CIM nas concentrações testadas do citronelal.

Tabela 2. Concentração Inibitória Mínima (CIM em $\mu \mathrm{g} / \mathrm{ml})$ do citronelal contra cepas de E. coli

\begin{tabular}{c|c|c}
\hline Cepas & Controle Positivo & Citronelal $(\boldsymbol{\mu g} / \mathbf{m L})$ \\
\hline $\mathrm{C}-18$ & + & $>1024$ \\
\hline 65 & + & $>1024$ \\
\hline 21 & + & $>1024$ \\
\hline $\mathrm{C}-20$ & + & $>1024$ \\
\hline $\mathrm{C}-24$ & + & $>1024$ \\
\hline $\mathrm{C}-25$ & + & $>1024$ \\
\hline 24 & + & $>1024$ \\
\hline 45 & + &
\end{tabular}

\section{DISCUSSÃO}

Os valores de CIM do citronelol variaram entre $256 \mu \mathrm{g} / \mathrm{ml}$ a $512 \mu \mathrm{g} / \mathrm{ml}$, enquanto que o citronelal não apresentou valores de CIM nas concentrações testadas.

Para produtos naturais, evidencia-se que fitoconstituintes que apresentem CIM de 50 a 500 $\mu \mathrm{g} / \mathrm{ml}$ são de ótima atividade, 600 a $1500 \mu \mathrm{g} / \mathrm{ml}$ de atividade moderada e superior a $1500 \mu \mathrm{g} / \mathrm{ml}$ considera-se de fraca atividade ${ }^{15}$. Assim, pode-se evidenciar que o fitoconstituinte citronelol apresentou atividade ótima para todas as cepas investigadas.

Corroborando com os resultados encontrados acerca do citronelal, em um estudo realizado com cepas Klebsiella pneumoniae produtora de ESBL, observou-se que não houve a inibição do crescimento em nenhuma das concentrações (32 a $2048 \mu \mathrm{g} / \mathrm{ml}$ ) testatadas pelos pesquisadores ${ }^{16}$.

Entretanto, tal achado não significa que o citronelal não apresente potencial antimicrobiano, podendo ser ativo frente a outros microrganismos, contudo neste estudo não apresentou atividade antibacteriana nas condições avaliadas. Ademais, é interessante que haja a aplicação de outras metodologias que permitam maior exploração desse 
possível potencial, como por exemplo, estudos de associação com fármacos utilizados na prática clínica ou outros produtos naturais, o que por sua vez, podem contribuir para a diminuição da concentração de ambos os fármacos ou ainda permitir a diminuição da seleção de cepas resistentes.

Diferindo dos resultados obtidos com o citronelol, observou-se em estudo realizado com as bactérias Streptococcus mutans, $S$. oralis e $S$. salivarius que o valor de CIM foi de $625 \mu \mathrm{g} / \mathrm{ml}^{17}$. Em pesquisa realizada com cepas de Trichophyton rubrum notou-se que o valores de CIM para citronelol variaram entre 8 a $1024 \mu \mathrm{g} / \mathrm{ml}^{18}$. Enquanto que em estudo com Cladosporium spp., resultados semelhantes foram encontrados, em que a CIM variou entre 256 a $512 \mu \mathrm{g} / \mathrm{ml}^{19}$.

A atividade antibacteriana obtida a partir do monoterpeno citronelol, pode estar relacionada a sua característica quimica hidrofóbica que, por sua vez, permite a adesão a lipídios da membrana celular e possível mudança de permeabilidade e integridade de membrana $^{20}$, causando portanto a morte do microrganismo.

Não obstante, é válido destacar que este é o primeiro estudo que busca evidenciar a atividade antimicrobiana de citronelol e citronelal frente a cepas de E.coli produtoras de ESBL, podendo, portanto, servir como material de apoio para o desenvolvimento de novos estudos que possuam a mesma temática como foco central.

\section{CONCLUSÃO}

Por meio da técnica de microdiluição e levando em considerações as condições experimentais aplicadas e as cepas testas, observouse que somente o monoterpeno citronelol apresentou atividade bacteriostática. Entretanto, a não evidenciação de atividade antibacteriana para 0 citronelal não significa que o mesmo não apresente possíveis atividades biológicas interessantes frente a microrganismos, sendo necessários outros estudos com a aplicação de outras técnicas para se caracterizar melhor o seu possível potencial.

\section{REFERÊNCIAS}

1. Souza CO, Melo TRB, Melo CSB, Menezes EM, Carvalho AC, Monteiro LCR. Escherichia coli enteropatogênica: uma categoria diarreiogênica versátil. Rev Pan-Amaz Saúde. 2016;7(2):79-91.

2. Lago A, Fuentefria SR, Fuentefria DP. Enterobactérias produtoras de ESBL em Passo Fundo, Estado do Rio Grande do Sul, Brasil. Rev Soc Bras Med Trop. 2010;43(4):430-34.

3. Rawat D, Nair D. Extended-spectrum $\beta$ lactamases in Gram negative bacteria. J Glob Infect Dis. 2010;2(3):263-74.

4. Rath S, Dubey D, Sahu MC, Padhy RN. Surveillance of ESBL producing multidrug resistant Escherichia coli in a teaching hospital in
India. Asian Pac J Trop Dis. 2014;4(2):140-49.

5. Song KH, Joen JH, Park WB, Park SW, Kim HB, $\mathrm{Oh} \mathrm{MD}$, et al. Clinical outcomes of spontaneous bacterial peritonitis due to extendedspectrum betalactamase-producing Escherichia coli and Klebsiella species: A retrospective matched casecontrol study. BMC Infect Dis. 2009;9.

6. Pitout JD, Laupland KB. Extended-spectrum betalactamase-producing Enterobacteriaceae: an emerging public-health concern. Lancet Infect Dis. 2008;8(3):159-66.

7. Coutinho HDM, Costa JGM, Lima EO, FalcãoSilva VS, Siqueira-Júnior JP. In vitro interference of Momordica charantia and chlorpromazine in the resistance to aminoglycosides. Pharm Biol. $2008 ; 47(11): 1056-59$.

8. Veras HNH, Rodrigues FFG, Botelho MA, Menezes IRA, Coutinho HDM, Costa JGM. Enhancement of aminoglycosides and b-lactams antibiotic activity by essential oil of Lippia sidoides Cham. and the Thymol. Arabian Journal of Chemistry. 2017;10(Sup 2):2790-95.

9. Felipe LO, Bicas JL. Terpenos, aromas e a química dos compostos naturais. Quím Nova Esc. 2017;39(2):120-30.

10. Bastos JF, Moreira IJ, Ribeiro TP, Medeiros IA, Antoniolli AR, Sousa DP, et al. Hypotensive and vasorelaxant effects of citronellol, a monoterpene alcohol, in rats. Basic Clin Pharmacol Toxicol. 2010;106:331-37

11. Castro HG, Perini VBM, Santos GR, Leal TCAB. Avaliação do teor e composição do óleo essencial de Cymbopogon nardus (L.) em diferentes épocas de colheita. Rev. Ciênc. Agron. 2010;41(2):308-14.

12. CLSI. Clinical and Laboratory Standards Institute. Metodologia dos Testes de Sensibilidade a Agentes Antimicrobianos para Bactérias de Crescimento Aeróbio: Norma Aprovada. 6nd ed. Pennsylvania: CLSI; c2005. 53 p.

13. Sarker SD, Nahar L, Kumarasamy Y. Microtitre plate-based antibacterial assay incorporating resazurin as an indicator of cell growth, and its application in the in vitro antibacterial screening of phytochemicals. Methods. 2007;42(4):321-24.

14. Hussain AI, Anwar F, Nigam OS, Sarker SD, Moore JE, et al. Antibacterial activity of some Lamiaceae essential oils using resazurin as na indicator of cell growth. Food Sci Technol. 2011; 44(4):1199-206.

15. Sartoratto A, Machado ALM, Delarmelina C, Figueira GM, Duarte MCT, Rehder VLG. Composition and antimicrobial activity of essential oils from aromatic plants used in Brazil. Braz J Microbiol. 2004;35(4):275-80.

16. Ponte MAN, Lima DS, Gomes SM, Santos BHC, Lima IO. Efeito inibitório de monoterpenos frente a Klebsiella pneumoniae produtoras de ESBL. R Bras Ci Saúde. 2018;22(1):51-6. 
17. Ferreira GLS, Bezerra LMD, Ribeiro ILA, Morais Júnior RCD, Castro RD. Susceptibility of cariogenic microorganisms to phytoconstituents. Braz J Biol. 2018;78(4):691-96.

18. Pereira FO, Mendes JM, Lima IO, Mota KS, Oliveira WA, Lima EO. Antifungal activity of geraniol and citronellol, two monoterpenes alcohols, against Trichophyton rubrum involves inhibition of ergosterol biosynthesis. Pharm biol. 2015;53(2):228-34.

19. Santos AS, Silva GS, Silva KVS, Lima MIO, Arrua JMM, Lima EO, et al. Antifungal activity of geraniol and citronellol against food-relevant dematiaceous fungi Cladosporium spp. Rev Inst Adolfo Lutz. 2017;76:1-8.

20. Kaur S, Rana S, Singh HP, Batish DR, Kohli RK. Citronellol disrupts membrana integrity by inducing free radical generation. Z Naturforsch $\mathrm{C}$. 2011;66(5-6):260-66.

\section{CONFLITO DE INTERESSES}

Os autores declaram não haver conflitos de interesse.

\section{AUTOR PARA CORRESPONDÊNCIA}

\section{Igara Oliveira Lima}

Universidade Federal de Campina Grande

igaralima@gmail.com

Submetido em 25/07/2019

Aceito em 20/04/2020 